\title{
An Investigation on Effect of Depth of Cut, Feed Rate and Tool Nose Radius on Induced vibration and Surface Roughness During hard Turning of $41 \mathrm{Cr} 4$ Alloy Steel using Response Surface Methodology
}

\author{
C. O. Izelu ${ }^{1, a^{*}}$, and S. C. Eze ${ }^{2, b}$ \\ ${ }^{1}$ Department of Mechanical Engineering, College of Technology, Federal University of Petroleum \\ Resources, Effurun, Nigeria \\ ${ }^{2}$ Department of mechanical Engineering, Faculty of Engineering, Nigerian Defence Academy, \\ Kaduna, Nigeria \\ aizelu2003@yahoo.com and coizelu@gmail.com \\ bsamchikeze@gmail.com and samezeng@yahoo.com
}

\begin{abstract}
Keywords: Depth of Cut, Feed Rate, Tool Nose Radius, Machining Induced Vibration, Surface Roughness, Hard Turning, Response Surface Methodology
\end{abstract}

\begin{abstract}
This paper describes an aspect of a set of turning experiments performed in attempt to model, predict and optimize the machining induced vibration and surface roughness as functions of the machining, tool and work-piece variables during hard turning of $41 \mathrm{Cr} 4$ alloy special steel, with standard cutting tool, on a conventional lathe. Amongst others, the input variables of interest include the depth of cut, feed rate and tool nose radius. The response surface methodology, based on central composite design of experiment, was adopted, with analysis performed in Design Expert 9 software environment. Quadratic regression models were suggested, and proved significant by an analysis of variance, for the machining induced vibration of the cutting tool and surface roughness of the work-piece. They also have capability of being used for prediction within limits. Analysis of variance also showed the depth of cut, feed rate and tool nose radius have significant effect on the machining induced vibration and surface roughness. Whereas the depth of cut has dominant effect on the machining induced vibration, the tool nose radius has dominant effect on the surface roughness. The optimum setting of the depth of cut of $1.33095 \mathrm{~mm}$, feed rate of $0.168695 \mathrm{~mm} / \mathrm{rev}$, and the tool nose radius of $1.71718 \mathrm{~mm}$ is required to minimize the machining induced vibration at $0.08 \mathrm{~mm} / \mathrm{s}^{2}$ and surface roughness at $6.056 \mu \mathrm{mm}$ with a desirability of 0.830 .
\end{abstract}

\section{Introduction}

A company's survival in global competition essentially depends on the quality of its products and services. Surface roughness, which is believed to have some level of dependence on the machining induced vibration, remains the most critical amongst the quality criteria as demand for quality and tight tolerances in metal cutting keep increasing. As an obligation for processes to work properly in time and at all times, it is of necessity that machined component manufacturers adopt better approaches to ensure that high quality products and services are produced. This drive for quality, and sometimes performance, has motivated efforts leading to the search for optimization techniques, and a shift from the use of traditional to non-traditional techniques, such as reviewed in Aggarwal and Singh [1]), and in Kumar and Uppal [2].

Amongst the non-traditional techniques, the use of response surface methodology (RSM) has attracted the attention of many researchers. As such, most aspects of the turning operations have been investigated using RSM in attempt to model, predict and optimize quality and performance characteristics as functions of the machining, tool, work-piece and environmental variables. Amongst these efforts, and relevant to this work, are the works of Ozcakar and Kasapoglu [3], Abhang and Hameedullah [4], Sahoo [5], Abhang and Hameedullah [6], Sastry and Devi [7], Srinivasan et al [8], Ramudu and Sastry [9], Aruna and Dhanalaksmi [10], Chomsamutr and Jongprasithporn [11], Abhang and Hameedullah [12], Manu et al [13], Makadia and Nanavati [14], Kannan et al [15], Phate and Tatwawadi [16], Bhuiyan and Ahmed [17], Manohar et al [18], 
Thiyagu et al [19], Saini and Parkash [20], Saini et al [21], Soni et al [22], Shunmugesh et al [23], Kumar [24], Sastry et al [25], Revankar et al [26], Mahajan et al [27], Shihab et al [28], and Gupta and Kohli [29]. Most recently, are the works of Khan et al [30], Devkumar et al [31], Devi et al [32], Rajpoot et al [33], Khidhir et al [34], Agrawal et al [35], Ranganath et al [36], and Chandra and Prasad [37]. The RSM as used in these works were based on a variety of design of experiment in which the generated data were analyze in a variety of software environment. Also, a variety of work-piece materials, cutting tools, lathe machines, and parameter measurement instruments were used; and a variety of process variables and constants, and performance variables were investigated; with results obtained from surface roughness data in close semblance. The works of Kassab and Khoshnaw [38], Han et al [39], Cahuc et al [40], Delijaicov et al [41], Rogov and siamak [42], [43] are equally relevant, but essential to the machining induced vibration of either the cutting tool or work-piece.

The same RSM, based on the central composite (CC) design of experiment, is used in this work to model, predict and optimize the machining induced vibration and surface roughness as functions of the tool nose radius, feed rate, and the depth of cut during hard turning of $41 \mathrm{Cr} 4$ alloy special steel, with a carbide cutting tool of the type F30, on a conventional lathe machine, using a surface roughness tester of the type ISR-16 and a vibration meter with transducer of the type $908 \mathrm{BE}$ for the measurement of the surface roughness and machining induced vibration, respectively. Data analysis was performed in Design Expert, version 9.2.6.1 environment.

\section{Materials, Equipment and Method}

Work-Piece Material. Chemical analysis and mechanical tests on sample of the selected workpiece material, was performed at Standards organization of Nigeria, Emene, Enugu, to establish its chemical composition and mechanical properties, respectively. The outcome, as given in Tables 1 and 2 , revealed it to be the $41 \mathrm{Cr} 4$ quenched and tempered (QT) alloy special steel. Its material number is 1.7035, and equivalent grades are SAE-AISI 5140, BS 530M40, EN 10083-3 or EN18, and VC140, which have no semblance with those previously investigated. FUHONG's technical report on special steels claims $41 \mathrm{Cr} 4$ to be one of the most widely used alloy steel. It recommends it for driving elements like crankshafts, front vehicle axles, axle journals and steering components. It also reveals that, after quenching and tempering (QT) heat treatment, $41 \mathrm{Cr} 4$ alloy steel has good overall mechanical properties, low temperature impact toughness and hardenability. It can get higher fatigue strength after oil cooling. Its machinability is good when subjected to normalizing and QT conditions, but its weldability is not good, and as a result, cannot easily be produce when subjected to welding conditions. For the turning experiment, specimen work-piece of this material are round bars (Fig. 1) having dimensions of diameter, $25 \mathrm{~mm}$, and length, $150 \mathrm{~mm}$.

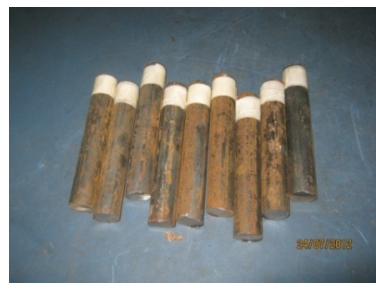

Fig. 1. Samples of 41Cr4 Alloy Steel Bars

Table 1. Chemical composition of $41 \mathrm{cr} 4$ alloy special steel

\begin{tabular}{clllll}
\hline & & \multicolumn{4}{c}{ Average elements \% } \\
Quality of material & Type of material & $\begin{array}{l}\text { Carbon } \\
(\mathrm{C})\end{array}$ & $\begin{array}{l}\text { Silicon } \\
\text { (Si) }\end{array}$ & $\begin{array}{l}\text { Manganese } \\
\text { (Mn) }\end{array}$ & $\begin{array}{l}\text { Chromium } \\
(\mathrm{Cr})\end{array}$ \\
\hline Quenched and Tempered Steel & $41 \mathrm{Cr} 4$ & 0.40 & 0.25 & 0.65 & 1.00 \\
\hline
\end{tabular}

Table 2. Mechanical properties of $41 \mathrm{cr} 4$ alloy special steel

\begin{tabular}{lcclcc}
\hline Sample ID & Diameter $(\mathbf{m m})$ & Area $\left(\mathbf{m m}^{2}\right)$ & BHN & Peak load (kN) & $\mathbf{U}_{\mathbf{t s}} \mathbf{N} / \mathbf{m m}^{2}$ \\
\hline Solid, Round & 10.00 & 78.55 & 278.48 & 70.92 & 902.83 \\
\hline
\end{tabular}


Processing Equipment. The turning experiment was conducted using a conventional lathe machine, that is, YUCY6240B Engine Lathe, with serial number: 2008031074 (Fig. 2a), and a carbide cutting tool of the type F30 (Fig. 2b). The tool insert has overall dimensions of $25 \mathrm{~mm} \times 25$ $\mathrm{mm} \times 12.5 \mathrm{~mm}$. It also has a back rake angle of $10^{\circ}$, side rake angle of $12^{\circ}$, side relief angle of $5^{\circ}$ and a side cutting edge angle of $15^{\circ}$.

(a)

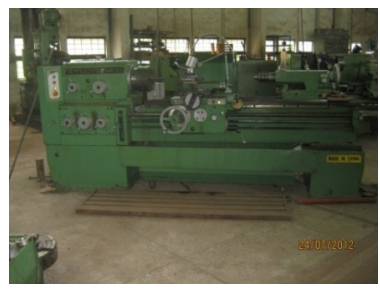

(b)

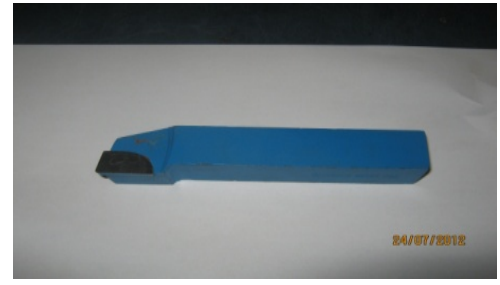

Fig. 2. (a) Conventional Lathe Machine; (b) Cutting Tool with Carbide Insert, F30

Table 3. Levels of the input variables

\begin{tabular}{llllrrr}
\hline & & & \multicolumn{4}{c}{ Levels } \\
S/N & Parameters & Notation & Unit & Low & Medium & High \\
\hline 1 & Tool Nose Radius & A & {$[\mathrm{mm}]$} & 0.0 & 1.0 & 2.0 \\
2 & Feed rate & B & {$[\mathrm{mm} / \mathrm{rev}]$} & 0.15 & 0.20 & 0.30 \\
3 & Depth of cut & C & {$[\mathrm{mm}]$} & 50 & 55 & 60 \\
\hline
\end{tabular}

Input Variables. Tool nose radius (A), feed rate (B) and depth of cut (C) are the selected process or input variables. Others were kept constant within experimental limits. Tool nose radius (A) is the radius of the tool cutting point. It is measured in $\mathrm{mm}$. Feed rate $(\mathrm{B})$ is the speed of the cutting tool relative to that of the work-piece as the tool takes a cut along the axis of the work-piece [2]. It is measured in mm per revolution. The depth of cut (C) is taken along the radius of the work-piece as the tool cuts into it in a turning operation [2]. It is measured in $\mathrm{mm}$. It is believed that these variables have influence on the surface roughness $\left(R_{a}\right)$ and machining induced vibration $\left(V_{i}\right)$, the extents of which are being investigated. Within limits as given in Table 3, the variables A, B and C can be set such as to minimize $R_{a}$ and $V_{i}$, and hence, improve on the quality of the machined part.

Output Variables. Surface roughness $\left(R_{a}\right)$ and machining induced vibration $\left(V_{i}\right)$ are the selected output or performance variables. According to Kumar and Uppal [2], $R_{a}$ is a measure of the texture of a surface. In quantitative terms, it is the vertical deviations of a real surface from its ideal form. Whereas a large deviation implies a rough surface, a small deviation implies a smooth surface. Hence, roughness of a surface is considered to be the high frequency, short wavelength component of a measured surface, and determines how a real object will interact with its environment. Note that, rough surfaces wear faster and have higher friction coefficient than smooth surfaces. Roughness of a surface may form nucleation sites for cracks or corrosion, promote adhesion, and may be very expensive to control in manufacturing. It is measured in microns, micro-meters or micro-millimeters. An inside surface roughness tester, ISR-16 (Fig. 3a) was selected for measurement of the surface roughness. Measurements of $R_{a}$ were taken at three different positions, which were located at $120^{\circ}$ on surface and about the axis of the work-pieces. The average of these values represented the surface texture of the turned surface. According to Sahoo [5], $R_{a}[\mu \mathrm{m}]$ is the center line average roughness. It is also known as the arithmetic deviation of the surface height from the mean line through the profile. The mean line separates the profile above and below it by equal area. 
(a)

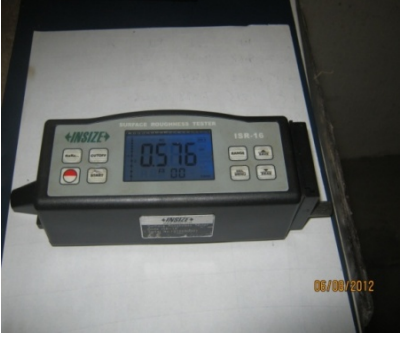

(b)

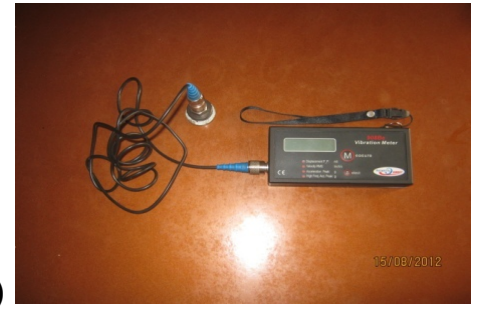

Fig. 3. (a) Surface Roughness Tester, ISR-16; (b) Vibration Meter with Transducer, 908 BE

During machining, vibrations may occur due to sudden clash of a tool against a work-piece, irregular tissues of the work-piece, regular excitation due to asymmetric torque, and due to bearing defects. A sudden clash of a tool against a work-piece occurs at the cutting zone, and has been referred to as self-excited vibration, or if excessive, as chatter [38], [39], [40]. Chatter may give rise defective machined surface, and excessive wear and breakage of the cutting tool. Self-excited vibration is induced at the cutting zone due to interaction of the cutting tool, chips and work-piece during machine, and therefore, is referred to here as machining induced vibration. It has influence on the surface roughness of machined components [41], [42], [43], but because it cannot be manipulated or controlled, though can be measured, it is treated here as a response variable, measured as an acceleration amplitude in $\mathrm{m} / \mathrm{s}^{2}$. A vibration meter with transducer, type $908 \mathrm{BE}$ (Fig. 3b), was selected for its measurement. The level of tool vibration was measured using a vertical data of a transducer mounted near to the tip and connected to the vibration meter. The data for each sample included amplitude of displacement and velocity of the point on the cutting tool. The acceleration, thereafter, was calculated from the relation between the displacement, velocity and acceleration.

Design and Analysis of Experiment. In order to minimize the number of runs or trials, optimize values of parameters, assess experimental error, make qualitative estimation of parameters, and to make inference regarding the effect of parameters on the characteristics of the process (Aggarwal and Singh, 2005), it is essential to adopt any of the techniques of design of experiment for the turning experiment. In this work the response surface methodology (RSM), based on central composite (CC) design of experiment (DOE), was selected for the modeling, prediction and optimization of $R_{a}$ and $V_{i}$ as functions of $\mathrm{A}, \mathrm{B}$ and $\mathrm{C}$ in the turning experiment. RSM is a mathematical as well as a statistical technique meant for the modeling and analysis of problems involving a response of interest as a function of several variables Sahoo [5]. It is adopted in machining process modeling and analysis to facilitate its optimization. Using RSM, machining response $Y$ may be defined as: $Y=\phi\left(x_{1}, x_{2}, \ldots, x_{i}\right) \pm e$, where $\phi\left(x_{1}, x_{2}, \ldots, x_{i}\right)$ is the response surface function in the form of a polynomial model, $x_{i}$ are the process variables and $e$ is the residual or experimental error. The second order polynomial or quadratic model may, therefore, be written as:

$$
\phi=\phi\left(x_{1}, x_{2}, \ldots, x_{k}\right)=(Y \pm e)=b_{0}+\sum_{i=1}^{k} b_{i} x_{i}+\sum_{i=1}^{k} b_{i i} x_{i}^{2}+\sum_{i=1}^{k} b_{i j} x_{i} x_{j}
$$

In this form (Eq. 1), the multiple regression model has linear, square and cross-product terms. It can satisfactorily be used to correlate dependent variables, $\phi_{j}$, with independent variables, $x_{i}$. The coefficients, $b_{0}, b_{i}, b_{i i}$ and $b_{i j}$ of the regression models may be estimated using a number techniques for design of experiment (DOE). For the problem studied the central composite (CC) was selected for the design of the turning experiment. Analysis of variance (ANOVA) was used to validate the developed models, and also, to predict the effect of selected factors $\mathrm{A}, \mathrm{B}$ and $\mathrm{C}$ on the response characteristics, $V_{i}$ and $R_{a}$. Optimization of the response functions, $V_{i}(A, B, C)$ and $R_{a}(A, B, C)$ subject to constraints as determined by the limits of the factors $\mathrm{A}, \mathrm{B}$ and $\mathrm{C}$ was performed as appropriate using standard optimization technique. The RSM was implemented in the Design Expert 9 software version 9.0 6.2 environment. 
Procedure of the Turning Experiment. In the setup of the turning experiment (Fig. 4), twentyseven (27) specimen $41 \mathrm{Cr} 4$ alloy steel bars (Fig. 1) were turned on the conventional lathe (Fig. 2a) with carbide tool insert (Fig. 2b) following a central composite (CC) design of experiment (DOE) in which factor combinations and sequence were appropriate for efficient data collection and analysis. Measurements of the machining induced vibration data were taken three times using a vibration transducer (Fig. 3b) placed on the tool post near the cutting zone. The data was transmitted to the vibration meter (Fig. 3b), and read out as displacement and velocity. The average cutting tool acceleration was determined from the general relations between displacement, velocity and acceleration. Also, measurements of the surface roughness were taken at three (3) different locations, $120^{\circ}$ from each other, on the machined surface using a surface roughness tester (Fig. 3a). The average values were recorded.

(a)

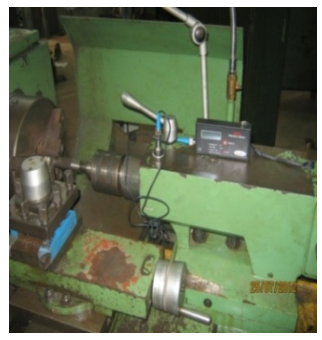

(b)

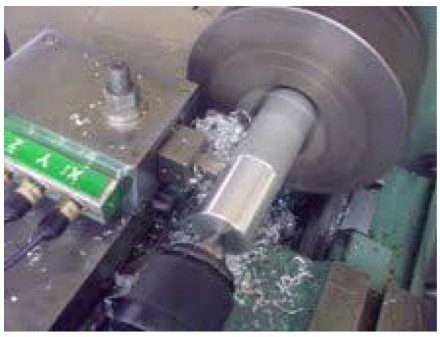

Fig. 4. Setup for the Turning Experiment

Table 4. Data generated from the turning experiment

\begin{tabular}{|c|c|c|c|c|c|c|}
\hline Standard & Run & $\begin{array}{c}\text { A } \\
\text { Tool Nose Radius } \\
{[\mathbf{m m}]}\end{array}$ & $\begin{array}{c}\text { B } \\
\text { Feed Rate } \\
{[\mathrm{mm} / \mathrm{rev}]}\end{array}$ & $\begin{array}{c}\text { C } \\
\text { Depth of Cut } \\
{[\mathrm{mm}]}\end{array}$ & $\begin{array}{c}V_{i} \\
\text { Acceleration Amplitude } \\
{\left[\mathbf{m m} / \mathbf{m i n}^{2}\right]}\end{array}$ & $\begin{array}{c}R_{a} \\
\text { Surface Roughness } \\
\text { [micro-mm] }\end{array}$ \\
\hline 1 & 5 & 0 & 0.15 & 1 & 0.18 & 8.930 \\
\hline 2 & 7 & 1 & 0.15 & 1 & 0.17 & 6.090 \\
\hline 3 & 19 & 2 & 0.15 & 1 & 0.04 & 6.878 \\
\hline 4 & 26 & 0 & 0.225 & 1 & 0.29 & 7.381 \\
\hline 5 & 1 & 1 & 0.225 & 1 & 0.24 & 5.280 \\
\hline 6 & 9 & 2 & 0.225 & 1 & 0.09 & 7.820 \\
\hline 7 & 14 & 0 & 0.3 & 1 & 0.42 & 8.320 \\
\hline 8 & 21 & 1 & 0.3 & 1 & 0.37 & 7.390 \\
\hline 9 & 6 & 2 & 0.3 & 1 & 0.18 & 10.910 \\
\hline 10 & 11 & 0 & 0.15 & 2 & 0.12 & 8.213 \\
\hline 11 & 22 & 1 & 0.15 & 2 & 0.19 & 5.520 \\
\hline 12 & 16 & 2 & 0.15 & 2 & 0.11 & 6.292 \\
\hline 13 & 23 & 0 & 0.225 & 2 & 0.15 & 6.895 \\
\hline 14 & 3 & 1 & 0.225 & 2 & 0.19 & 5.690 \\
\hline 15 & 18 & 2 & 0.225 & 2 & 0.12 & 7.149 \\
\hline 16 & 27 & 0 & 0.3 & 2 & 0.22 & 8.319 \\
\hline 17 & 17 & 1 & 0.3 & 2 & 0.24 & 7.230 \\
\hline 18 & 13 & 2 & 0.3 & 2 & 0.16 & 11.440 \\
\hline 19 & 20 & 0 & 0.15 & 3 & 0.29 & 6.620 \\
\hline 20 & 25 & 1 & 0.15 & 3 & 0.43 & 4.390 \\
\hline 21 & 24 & 2 & 0.15 & 3 & 0.44 & 5.790 \\
\hline 22 & 8 & 0 & 0.225 & 3 & 0.27 & 5.570 \\
\hline 23 & 12 & 1 & 0.225 & 3 & 0.39 & 4.447 \\
\hline 24 & 15 & 2 & 0.225 & 3 & 0.37 & 7.436 \\
\hline 25 & 4 & 0 & 0.3 & 3 & 0.29 & 7.280 \\
\hline 26 & 2 & 1 & 0.3 & 3 & 0.37 & 6.610 \\
\hline 27 & 10 & 2 & 0.3 & 3 & 0.36 & 10.980 \\
\hline
\end{tabular}




\section{Results and Discussion}

All factors that could introduce error were duly considered and minimized as appropriate when conducting the turning experiment. Table 4 shows the data generated from the turning experiment. Results of its analysis in the environment of the Design Expert software, version 9.0.6.2, are presented and discussed as follows:

Machining Induced Vibration Data. Table 5 is the model summary statistics. It suggests a quadratic model to be more accurate as predicted by the least of the standard deviation of 0.008338 and PRESS of 0.003038 , and also, the highest of the adjusted R-square of 0.9947 and predicted Rsquare of 0.9911. As a result the model terms are significant, and the model is not aliased. Table 6 is ANOVA for the response surface quadratic model for $V_{i}$. It confirms the significance of the model, and its capability for accurate prediction of $V_{i}$ within the selected limits. It also, confirms the model terms $\mathrm{A}, \mathrm{B}, \mathrm{C}, \mathrm{A}^{2}, \mathrm{~B}^{2}, \mathrm{C}^{2}, \mathrm{AC}, \mathrm{AB}$ and $\mathrm{BC}$ as being significant, and good predictors of $V_{i}$. For the linear terms, $\mathrm{C}$ has dominant influence on $V_{i}$ followed by $\mathrm{B}$, and then, $\mathrm{A}$. For the square terms, $\mathrm{C}^{2}$ has dominant influence on $V_{i}$ followed by $\mathrm{A}^{2}$, and the $\mathrm{B}^{2}$. For cross-products terms, AC has dominant influence on $V_{i}$ followed by BC, and then, AB. In Table 7, the predicted $\mathrm{R}$-square of 0.9911 is found to be in reasonable agreement with the adjusted R-square of 0.9947 since the difference of 0.0036 is less than 0.2 . The adequacy precision of 79.796 , greater than 4 , is a desirable signal to noise ratio. This indicates that there is adequate signal, and that this model can be used to navigate the design space.

Table 5. Model summary statistics

\begin{tabular}{rrrrrrr}
\hline Source & $\begin{array}{l}\text { Standard } \\
\text { Deviation }\end{array}$ & R-Squared & $\begin{array}{l}\text { Adjusted } \\
\text { R-Squared }\end{array}$ & $\begin{array}{l}\text { Predicted } \\
\text { R-Squared }\end{array}$ & \multicolumn{1}{l}{ PRESS } & \\
\hline Linear & 0.100 & 0.3310 & 0.2438 & 0.0517 & 0.32 & \\
2FI & 0.076 & 0.6655 & 0.5651 & 0.4607 & 0.18 & \\
Quadratic & $8.338 \mathrm{E}-003$ & 0.9965 & 0.9947 & 0.9911 & $3.038 \mathrm{E}-003$ & Suggested \\
Cubic & $9.125 \mathrm{E}-003$ & 0.9976 & 0.9937 & 0.9744 & $8.737 \mathrm{E}-003$ & Aliased \\
\hline
\end{tabular}

Table 6. ANOVA for response surface quadratic model for acceleration amplitude

\begin{tabular}{|c|c|c|c|c|c|}
\hline Source & $\begin{array}{l}\text { Sum of } \\
\text { Squares }\end{array}$ & $\begin{array}{l}\text { Degree of } \\
\text { Freedom }\end{array}$ & $\begin{array}{l}\text { Mean } \\
\text { Square }\end{array}$ & $\begin{array}{l}\text { F } \\
\text { Value }\end{array}$ & $\begin{array}{l}\text { p-value } \\
\text { Prob }>\text { F }\end{array}$ \\
\hline Model & 0.34 & 9 & 0.038 & 543.84 & $<0.0001$ \\
\hline A-Tool Nose Radius & $7.041 \mathrm{E}-003$ & 1 & $7.041 \mathrm{E}-003$ & 101.29 & $<0.0001$ \\
\hline B-Feed Rate & 0.022 & 1 & 0.022 & 323.27 & $<0.0001$ \\
\hline C-Depth of Cut & 0.084 & 1 & 0.084 & 1201.25 & $<0.0001$ \\
\hline $\mathrm{AB}$ & $4.563 \mathrm{E}-003$ & 1 & $4.563 \mathrm{E}-003$ & 65.64 & $<0.0001$ \\
\hline $\mathrm{AC}$ & 0.067 & 1 & 0.067 & 962.41 & $<0.0001$ \\
\hline $\mathrm{BC}$ & 0.043 & 1 & 0.043 & 614.57 & $<0.0001$ \\
\hline $\mathrm{A}^{\wedge} 2$ & 0.021 & 1 & 0.021 & 308.43 & $<0.0001$ \\
\hline $\mathrm{B}^{\wedge} 2$ & $2.454 \mathrm{E}-003$ & 1 & $2.454 \mathrm{E}-003$ & 35.30 & $<0.0001$ \\
\hline $\mathrm{C}^{\wedge} 2$ & 0.089 & 1 & 0.089 & 1282.35 & $<0.0001$ \\
\hline Residual & $1.182 \mathrm{E}-003$ & 17 & $6.951 \mathrm{E}-005$ & & \\
\hline Cor Total & 0.34 & 26 & & & \\
\hline
\end{tabular}

Table 7. Quadratic model statistics

\begin{tabular}{lrll}
\hline Standard Deviation & $8.338 \mathrm{E}-003$ & R-Squared & 0.9965 \\
Mean & 0.25 & Adjusted R-Squared & 0.9947 \\
C.V. \% & 3.36 & Predicted R-Squared & 0.9911 \\
PRESS & 3.038 E-003 & Adequacy Precision & 79.796 \\
\hline
\end{tabular}


The response surface models for $V_{i}$, given in terms of the coded and actual factors A, B and C, as in Eq. 2 and Eq.3, respectively, are:

$$
\begin{aligned}
V_{i}= & 0.19-0.02 A+0.035 B+0.068 C-0.019 A B+0.075 A C \\
& -0.06 B C-0.06 A^{2}+0.02 B^{2}+0.12 C^{2} \\
V_{i}= & 0.3132+0.00894 A+0.70444 B-0.31511 C-0.26 A B+0.074667 A C \\
& -0.79556 B C-0.059778 A^{2}+3.59506 B^{2}+0.12189 C^{2}
\end{aligned}
$$

In Fig 5a, a plot of the predicted values of $V_{i}$, generated from Eq. 3, against the actual values $V_{i}$ illustrates how well the predicted $V_{i}$ data fits the actual data. In Fig 5b, the machining induced vibration $V_{i}$ is found to have nonlinear relationship with factors A, B and C. Effect of these factors on $V_{i}$ became much more significant at the higher levels of these factors, when compared to that at lower levels. At higher levels of these factors, $V_{i}$ decreased with increase in A, but increased with increase in $\mathrm{B}$ and $\mathrm{C}$ from the reference point. At lower levels of the factors, $V_{i}$ increased with increase in $\mathrm{A}$, but decreased with increase in $\mathrm{B}$ and $\mathrm{C}$ toward the reference point. The implication of the behavior is that $V_{i}$ is minimized when the factors except $\mathrm{A}$ are set at lower level of their values. These behaviors can also be seen in the contour and response surface plots given in Figs 6 to 8. It can as well be attributed to the observed multiple interaction between factors.

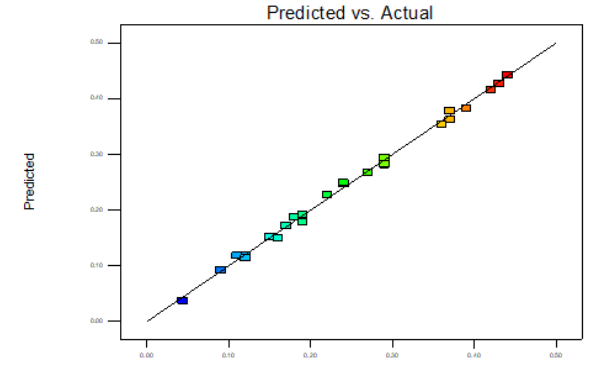

(a)

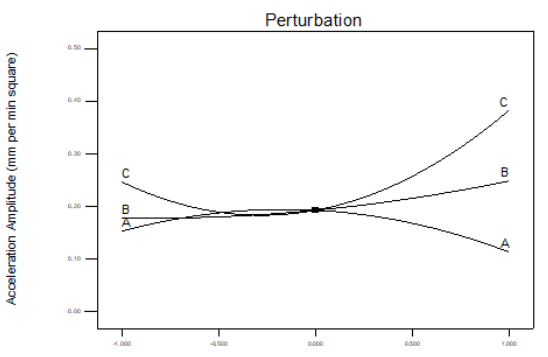

(b)

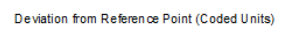

Fig. 5. (a) A Plot of the Predicted $V_{i}$ against the Actual values; (b) A Plot of $V_{i}$ against the deviation from reference point (Coded Unit) or perturbation

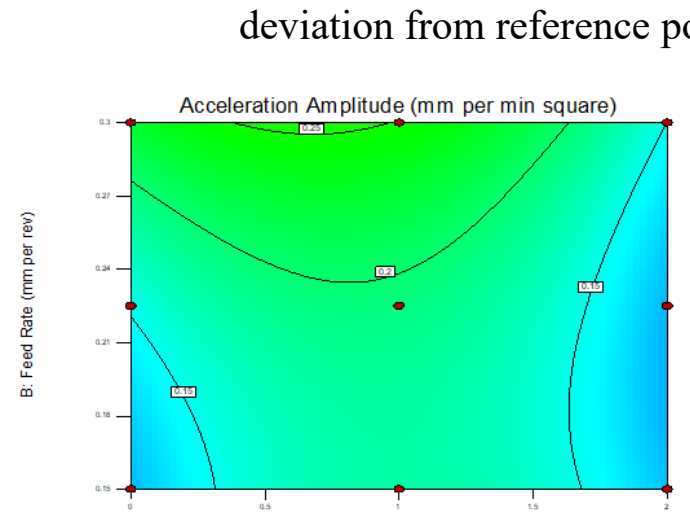

(a)

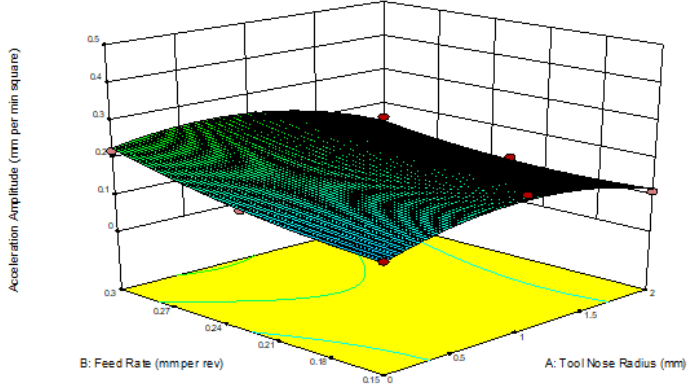

(b)

Fig. 6. (a) A Contour plot of $V_{i}$ against $\mathrm{A}$ and $\mathrm{B}$ with $\mathrm{C}$ set at $2 \mathrm{~mm}$; (b) A Response Surface plot of $V_{i}$ against $\mathrm{A}$ and $\mathrm{B}$ with $\mathrm{C}$ set at $2 \mathrm{~mm}$ 


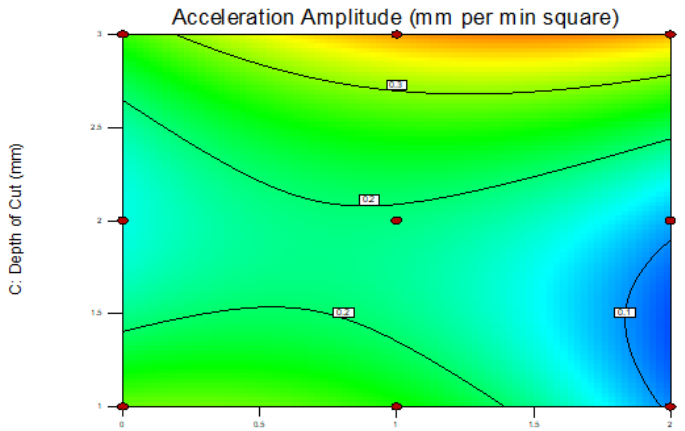

(a)

A: Tool Nose Radiving

Fig. 7. (a) A Contour plot of $V_{i}$ against $\mathrm{A}$ and $\mathrm{C}$ with B set at $0.225 \mathrm{~mm} / \mathrm{rev}$; (b) A Response Surface plot of $V_{i}$ against $\mathrm{A}$ and $\mathrm{C}$ with B set at $0.225 \mathrm{~mm} / \mathrm{rev}$

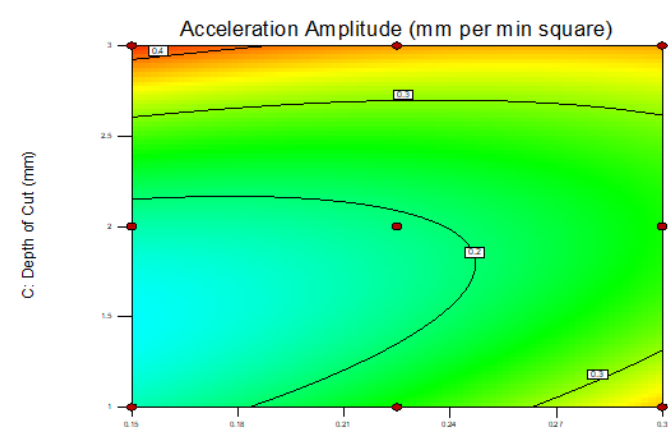

(a)
B: Feed Rate (mm per rev)

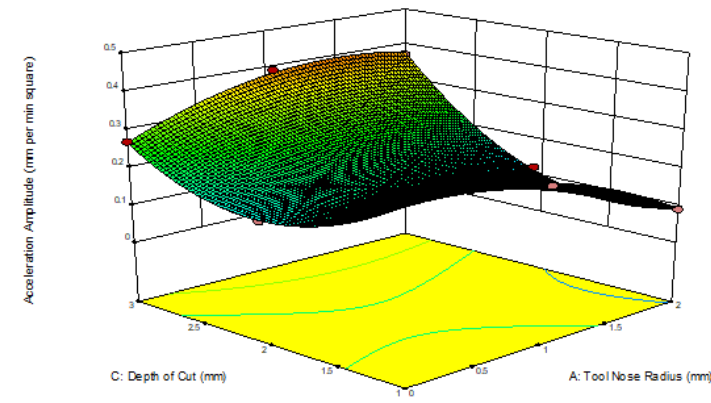

(b)

Fig. 8. (a) A Contour plot of $V_{i}$ against B and C with A set at $1 \mathrm{~mm}$; (b) A Response Surface plot of $V_{i}$ against $\mathrm{B}$ and $\mathrm{C}$ with $\mathrm{A}$ set at $1 \mathrm{~mm}$

Surface Roughness Data. In Table 8, the model summary statistics reveals a quadratic regression model suggested as being adequate for accurate fitting of the surface roughness data. It recorded a standard deviation of 0.28 , R-square value of 0.9839 , adjusted R-square value of 0.9754 , and predicted R-square value of 0.9654. In Table 9, analysis of variance (ANOVA) shows the model is significant for accurate prediction of the surface roughness $R_{a}$ within the design limits of factors A, $\mathrm{B}$ and $\mathrm{C}$. The influence of model terms, $\mathrm{A}, \mathrm{B}, \mathrm{C}, \mathrm{A}^{2}, \mathrm{~B}^{2}, \mathrm{C} 2, \mathrm{AB}, \mathrm{AC}$ and $\mathrm{BC}$ on $R_{a}$ is equally shown to be significant. For the linear terms, B has dominant influence on $R_{a}$ followed by $\mathrm{C}$, and then, A. Whereas, for the square terms, $\mathrm{A}^{2}$ has dominant influence on $R_{a}$ when compare to $\mathrm{B}^{2}$, the least being $\mathrm{C}^{2}$. For the cross-product terms, $\mathrm{AB}$ has dominant influence on $R_{a}$ followed by $\mathrm{AC}$, with the least being BC. The quadratic model statistics, given in Table 10, shows the predicted Rsquare value of 0.8903 is in reasonable agreement with the adjusted $\mathrm{R}$-square value of 0.9270 , since the difference of 0.0367 is less than 0.2 . The adequacy precision of 22.671 , greater than 4 , is a desirable signal to noise ratio. This indicates that there is adequate signal, and that this model can also be used to navigate the design space.

Table 8. Model summary statistics

\begin{tabular}{rrrrrrr}
\hline Source & $\begin{array}{l}\text { Std. } \\
\text { Dev. }\end{array}$ & R-Squared & $\begin{array}{l}\text { Adjusted } \\
\text { R-Squared }\end{array}$ & $\begin{array}{l}\text { Predicted } \\
\text { R-Squared }\end{array}$ & PRESS & \\
\hline Linear & 1.55 & 0.3528 & 0.2684 & 0.0945 & 76.89 & \\
2FI & 1.34 & 0.5759 & 0.4487 & 0.2154 & 66.63 & \\
Quadratic & 0.28 & 0.9839 & 0.9754 & 0.9654 & 2.94 & Suggested \\
Cubic & 0.25 & 0.9926 & 0.9808 & 0.9619 & 3.23 & Aliased \\
\hline
\end{tabular}


Table 9. ANOVA for response surface quadratic model for surface roughness

\begin{tabular}{lrlrrrl}
\hline & SUM OF & \multicolumn{1}{l}{ DEGREE OF } & \multicolumn{1}{l}{ MEAN } & F & P-VALUE & \\
SOURCE & SQUARES & FREEDOM & SQUARE & VALUE & PROB $>$ F & \\
\hline MODEL & 83.55 & 9 & 9.28 & 115.53 & $<0.0001$ & SIGNIFICANT \\
A-TOOL NOSE RADIUS & 2.85 & 1 & 2.85 & 35.52 & $<0.0001$ & \\
B-FEED RATE & 21.68 & 1 & 21.68 & 269.86 & $<0.0001$ & \\
C-DEPTH OF CUT & 5.42 & 1 & 5.42 & 67.44 & $<0.0001$ & \\
AB & 16.84 & 1 & 16.84 & 209.54 & $<0.0001$ & \\
AC & 1.18 & 1 & 1.18 & 14.65 & 0.0013 & \\
BC & 0.93 & 1 & 0.93 & 11.63 & 0.0033 & \\
$\mathrm{~A}^{\wedge} 2$ & 25.25 & 1 & 25.25 & 314.31 & $<0.0001$ & \\
$\mathrm{~B}^{\wedge} 2$ & 8.85 & 1 & 8.85 & 110.20 & $<0.0001$ & \\
$\mathrm{C}^{\wedge} 2$ & 0.53 & 1 & 0.53 & 6.66 & 0.0195 & \\
RESIDUAL & 1.37 & 17 & 0.080 & & & \\
COR TOTAL & 84.91 & 26 & & & & \\
\hline
\end{tabular}

Table 10. Quadratic model statistics

\begin{tabular}{llll}
\hline Standard Deviation & 0.28 & R-Squared & 0.9839 \\
Mean & 7.22 & Adjusted R-Squared & 0.9754 \\
C.V. \% & 3.93 & Predicted R-Squared & 0.9654 \\
PRESS & 2.94 & Adequacy Precision & 40.321 \\
\hline
\end{tabular}

The response surface models of the surface roughness $\left(R_{a}\right)$, given in terms of the coded factors (Eq. 5) and actual factors (Eq. 6), are given as follows:

$$
\begin{aligned}
R_{a}= & 5.24+0.4 A+1.1 B-0.55 C+1.18 A B+0.31 A C \\
& +0.28 B C+2.05 A^{2}+1.21 B^{2}-0.3 C^{2} \\
R_{a}= & 20.28974-7.88505 A-105.78148 B-0.50469 C+15.79333 A B \\
& +0.31325 A C+3.72 B C+2.05161 A^{2}+215.96049 B^{2}-0.29856 C^{2}
\end{aligned}
$$

As given in Fig 9a the values of the surface roughness, $R_{a}$, as predicted, are generated from Eq. 6, and a plot of $R_{a}$ against its actual values illustrates how well the predicted $R_{a}$ data fits the actual data. As shown in Fig 9b, $R_{a}$ has nonlinear relationship with factors $\mathrm{A}, \mathrm{B}$ and $\mathrm{C}$, and that the influence of these factors on $R_{a}$ is equally significant at lower and higher levels. It is important to note that at higher levels of these factors, $R_{a}$ increased with increase in $\mathrm{A}$ and $\mathrm{B}$, but decreased with increase in $\mathrm{C}$ from the reference point; and that, at lower levels of the factors, $R_{a}$ decreased with increase in $\mathrm{A}$ and $\mathrm{B}$, but increased with increase in $\mathrm{C}$ toward the reference point. These behaviors have implication of $R_{a}$ being minimized when the factors $\mathrm{A}$ and $\mathrm{B}$ are set at the neighbourhood of the intermediate level of their values, and the factor $\mathrm{C}$ set either at the extreme low or high level of its value. They can also be seen in the contour and response surface plots given in Figs 10 to 12. They can be attributed to the observed multiple interactions of factors. 

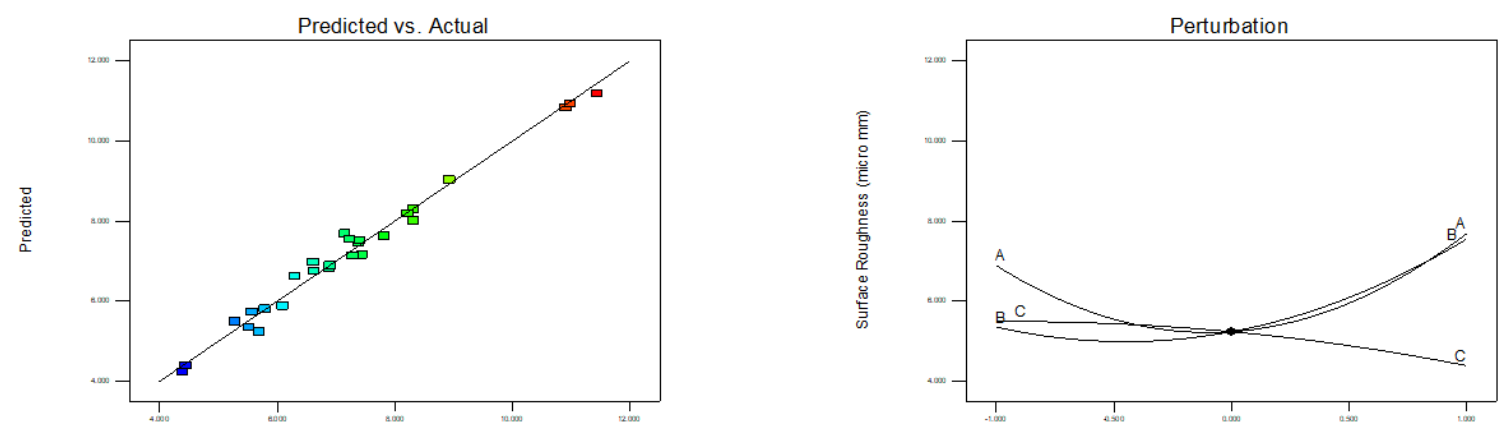

(a)

(b)

Deviation from Reference Point (Coded Units)

Fig. 9. (a) A Plot of the Predicted $R_{a}$ against the Actual values; (b) A Plot of $R_{a}$ against the deviation from reference point (Coded Unit) or perturbation

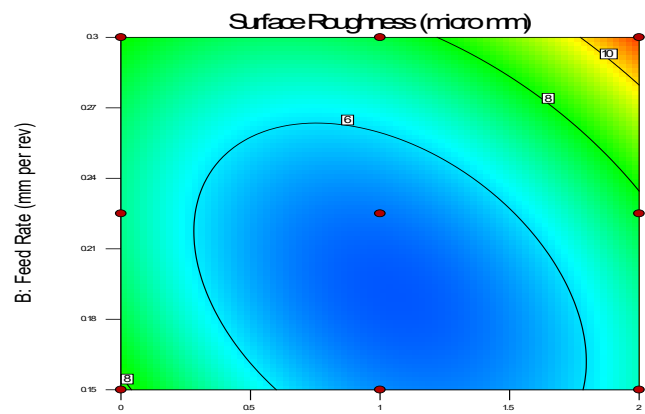

(a)

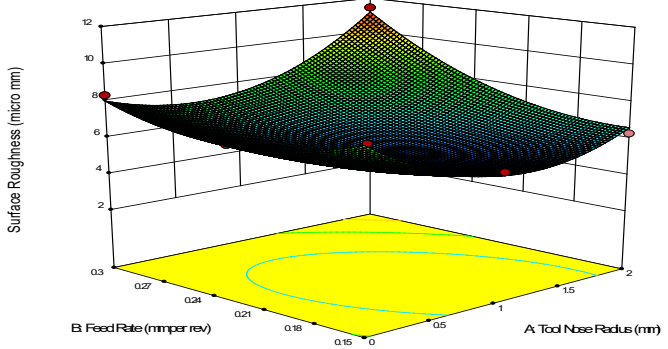

(b)

Fig. 10. (a) A Contour plot of $R_{a}$ against $\mathrm{A}$ and B with $\mathrm{C}$ set at $2 \mathrm{~mm}$; (b) A Response Surface plot of $R_{a}$ against $\mathrm{A}$ and $\mathrm{B}$ with $\mathrm{C}$ set at $2 \mathrm{~mm}$

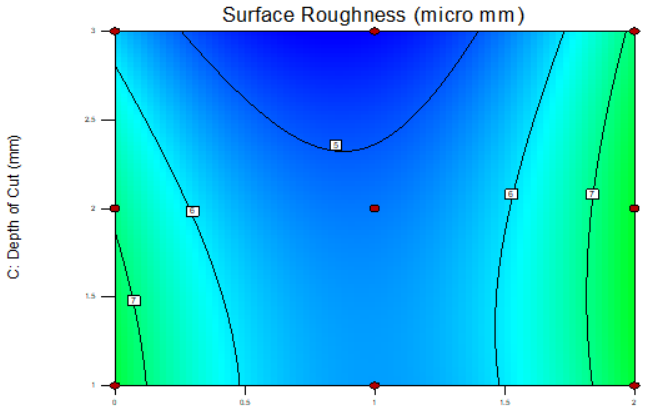

(a)
A. Tool Nose Radius (mm) (b)

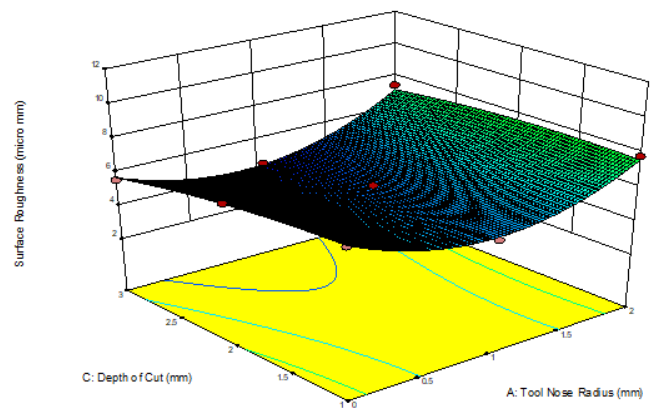

Fig. 11. (a) A Contour plot of $R_{a}$ against A and C with B set at $0.225 \mathrm{~mm} / \mathrm{rev}$; (b) A Response Surface plot of $R_{a}$ against A and C with B set at $0.225 \mathrm{~mm} / \mathrm{rev}$ 


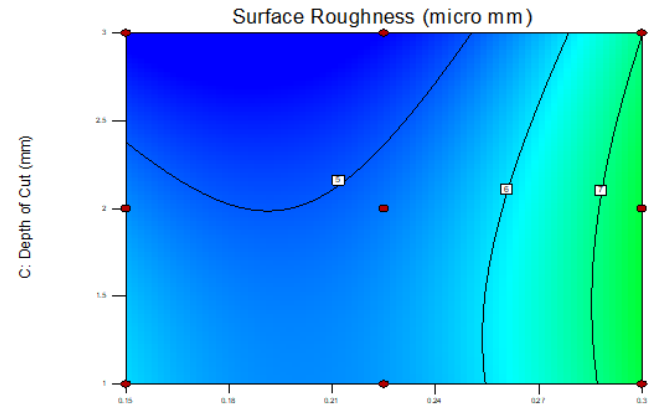

(a)
B: Feed Rate (mm per rev) (b)

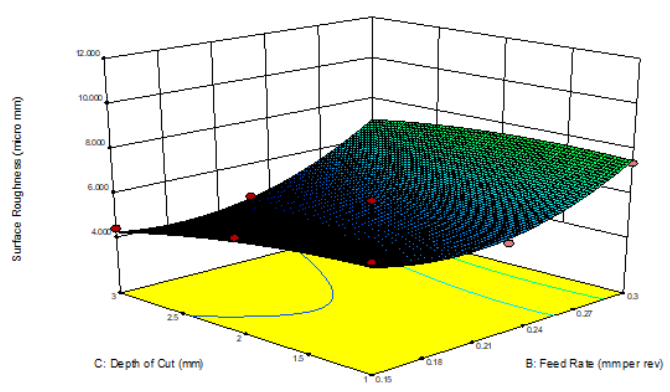

Fig. 12. (a) A Contour plot of $R_{a}$ against $\mathrm{B}$ and $\mathrm{C}$ with A set at $1 \mathrm{~mm}$; (b) A Response Surface plot of $R_{a}$ against $\mathrm{B}$ and $\mathrm{C}$ with $\mathrm{A}$ set at $1 \mathrm{~mm}$

Parameter Optimization. The two undesirable as well as uncontrollable process characteristics that are required to be minimized to improve on product quality are the machining induced vibration $\left(V_{i}\right)$ of the cutting tool, and the surface roughness $\left(R_{a}\right)$ of the specimen work-piece. Both were measured using standard instruments in the turning experiment. As given in the ramps of Fig 23, the optimum setting of the factors, $\mathrm{A}$ at $1.71718 \mathrm{~mm}, \mathrm{~B}$ at $0.158695 \mathrm{~mm} / \mathrm{rev}$, and $\mathrm{C}$ at 1.133095 $\mathrm{mm}$, would minimize $V_{i}$ to a value of $0.08 \mathrm{~mm} / \mathrm{s}^{2}$ and $R_{a}$ to a value of $6.056 \mu \mathrm{mm}$ with desirability of 0.830 , which occurred within the selected design space. As shown in Fig 13 and confirmed by the contour and surface plots of Figs 10 to $12, V_{i}$ and $R_{a}$ are both minimized at lower values of B and $\mathrm{C}$, and higher value $\mathrm{A}$.

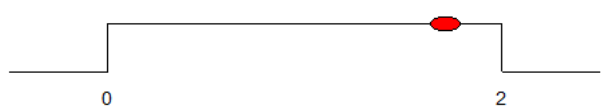

A: Tool Nose Radius $=1.71718$

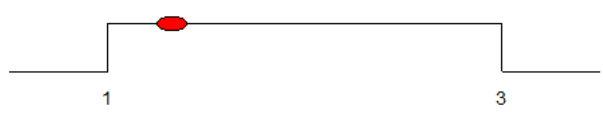

C: Depth of $\mathrm{Cu}=1.33095$

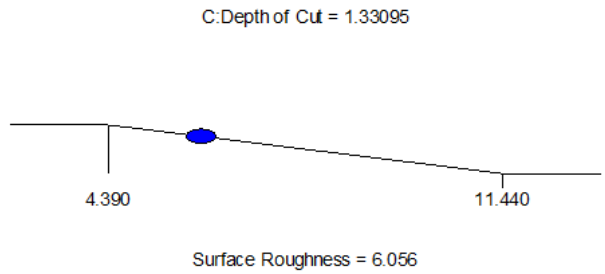

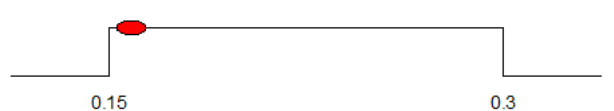

B:Feed Rate $=0.158695$

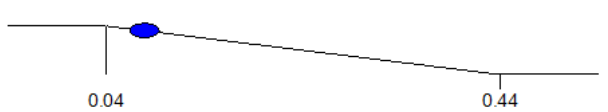

Acceleration Amplitude $=0.08$

Desirability $=0.830$

Fig. 13. Optimum Setting of the Process Variables, which Minimized the Surface Roughness and Machining Induced Vibration

Surface Roughness vs Machining Induced Vibration. As expected, machining induced vibration $\left(V_{i}\right)$ should have influence on surface roughness $\left(R_{a}\right)$ as it impacts negatively on the cutting zone in the turning operations. However, as shown in the plot of $R_{a}$ versus $V_{i}$ given in Fig 14, there is nonlinear relationship, but no significant correlation between these process characteristics within the experimental design limits as can be seen from the R-square value of the trend line of 0.0561 , but there may be correlation outside these limits. 


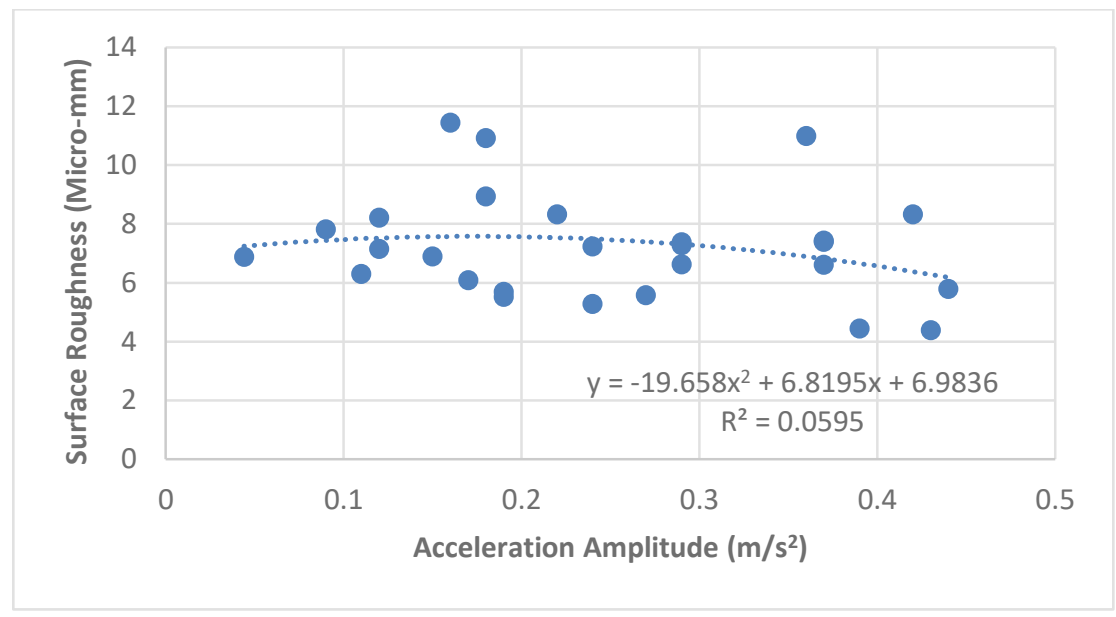

Fig. 14. A plot of $R_{a}$ against $V_{i}$

\section{Conclusion}

The response surface methodology, based on the central composite design of experiment was used to model, predict and optimize the machining induced vibration of the cutting tool and surface roughness of the work-piece as functions of the tool overhang, feed rate and depth of cut. A turning experiment was conducted on $41 \mathrm{Cr} 4$ alloy special steel on conventional lathe with standard cutting tool and response parameters measuring instruments. Analyses and optimization of the response characteristics data was performed in the Design Expert version 9.0.6.2 software environment. It was found that:

a. Within limits of the selected factors, the developed quadratic regression models can be used for accurate prediction of the selected process and quality characteristics.

b. A Nonlinear relationship was found to exist between the machining induced vibration of the cutting tool and the tool nose radius, feed rate and depth of cut. At the higher levels of their values, the effect of these factors on the machining induced vibration is more significant when compared to the same effect at lower levels of their values. The machining induced vibration would be minimized when the factors are set at values within the lower levels of the factors near the reference point. An exception is the tool nose radius whose value must be set at higher level away from the reference point.

c. Also a nonlinear relationship was found to exist between the surface roughness of the workpiece and the tool nose radius, feed rate and depth of cut. The effect of the tool nose radius and feed rate on the surface roughness are quite significant both at lower and higher levels of their values. There is no significant effect of the depth of cut on these parameters. The surface roughness is minimized at neighbourhood of the intermediate levels of the factors. An exception is the depth of cut whose value set at the high level would lead to minimization of the surface roughness

d. Within the selected design space, the optimum setting of the considered factors, A at $1.71718 \mathrm{~mm}, \mathrm{~B}$ at $0.158695 \mathrm{~mm} / \mathrm{rev}$, and $\mathrm{C}$ at $1.133095 \mathrm{~mm}$, would minimize $V_{i}$ to a value of $0.08 \mathrm{~mm} / \mathrm{s}^{2}$ and $R_{a}$ to a value of $6.056 \mu \mathrm{mm}$ with desirability of 0.830 .

e. There is nonlinear relationship and no significant correlation between the surface roughness and the machining induced vibration, as can be seen from the R-square value of 0.0595 . This is possible only within the selected design space. However, there may be correlation outside this limits. 


\section{References}

[1] Aggarwal, A. and Singh, H., Optimization of Machining Techniques - A retrospective and literature review, Sadhana, Vol. 30, Part 6 (2005) 699 - 711

[2] Kumar, N. and Uppal, N., A Review on Various Optimization Techniques used in Turning Operation for Improving Surface Roughness, Mechanica Confab, Vol. 2, No. 4 (2013) 45 -51

[3] Ozcakar, N. and Kasapogu, O. A., Modeling of Surface Roughness in Machining, Yontim, Yil 20, Saya 64 (2009) $27-40$

[4] Abhang, L. B. and Hameedullah, M., Power Prediction Model for Turning EN-31 Steel Using Response Surface Methodology, Journal of Engineering Science and Technology Review, Vol. 3, No. 1 (2010) $116-122$

[5] Sahoo, P., Optimization of Turning Parameters for Surface Roughness using RSM and GA, Advances in Production Engineering and Management, Vol. 6, No. 3 (2011) 197 - 208

[6] Abhang, L. B. and Hameedullah, M., Optimization of Power Consumption by Desirability Function Approach, International journal on Resent Trends in Engineering and Technology. Vol. 6, No. 2 (2011) $287-290$

[7] Sastry, M.N. and Devi, K.D., Optimization of Performance Measures in CNC Turning using Design of experiment (RSM), Science Insight: An International Journal, Vol.1, No. 1(2011)1-5

[8] Srinivasan, A., Arunachalam, R. M., Ramesh, S. and Senthilkumaar, J. S., Machining Performance Study on Metal matrix Composites - A Response Surface Methodology Approach, American Journal of Applied Science, Vol. 9, No. 4 (2012) 478 - 483

[9] Ramudu, C. and Sastry, M. N., Analysis and Optimization of Turning Process Parameters using Design of Experiment, International journal of Engineering Research and Applications, Vol. 2, issue 6 (2012) $020-027$

[10] Aruna, M. and Dhanalaksmi, V., Design Optimization of Cutting Parameters when Turning Inconel 718 with Cermet Inserts, International Journal of Mechanical and Aerospace Engineering, vol. 6 (2012) $187-190$

[11] Chomamutr, K. and Jongprasithporn, S., Optimization Parameters of Tool Life Model using the Taguchi Approach and Response Methodology, International Journal of Computer Science Issues, Vol. 9, Issue 1, No. 3 (2012) 120 - 125

[12] Abhang, L. B. and Hameedullah, M., Optimal Machining Parameters for Achieving the Desired Surface Roughness in Turning of Steel, Technical Journal of Engineering Research (TJER), Vol. 9, No. 1 (2013) $37-45$

[13] Manu, R., Akbar, B. S., and Sharmas, V. S., Predictive Machinability Model of Hardened Steel Material in Turning Operation by Response Surface Regression Method, International Journal of Applications or Innovation in Engineering and Management, Vol. 2, Issue 10 (2013) 330 334

[14] Makadia, A. J. and Nanavati, J. I., Optimization of Machining Parameters for Turning Operations Based on Response Surface Methodology, Measurement, Elsevier, Vol. 46 (2013) $1521-1529$

[15] Kannan, A., Esakkiraja, K. and Mataraj, M., Modeling and Analysis for Cutting Temperature in Turning of Aluminium 6063 using Response Surface Methodology, Journal of Mechanical and Civil Engineering, Vol. 9, Issue 4 (2013) $59-64$

[16] Phate, M. and Tatwawadi, V. H., Formulation of a Field Data Based Model for a surface Roughness using Response Surface Method, International Journal of Science, Engineering and Technology Research, Vol. 2, Issue 4 (2013) 793 - 798

[17] Bhulyan, T. H. and Ahmed, I., Optimization of Cutting Parameters in Turning Process, Journal of Production Engineering, Vol. 16, No. 2 (2013) 11 - 19

[18] Manohar, M., Joseph, J., Selvaraj, T. and Sivakumar, D., Application of Box Behnken Design to Optimize the Parameters for Turning Inconel 718 using Carbide Tools, International Journal of scientific and Engineering Research, Vol. 4, Issue 4 (2013) 620 - 642 
[19] Thiyagu, M., Karunamoorthy, L. and Arunkumar, N., Experimental Studies in machining Duplex Stainless Steel using Response Surface Methodology, International Journal of Mechanical Engineering, Vol. 14, No. 3 (2014) 48 - 61

[20] Saini, P. and Parkash, S., A Multi Response Optimization of Machining Parameters for Surface Roughness and MRR in High Speed CNC Turning of EN-24 Alloy Steel using Response Surface Methodology, International Journal of Engineering Science and Research Technology, Vol. 3, Issue 9 (2014) 333 - 345

[21] Saini, P., Parkash, S. and Choudhary, D., Experimental Investigation of Machining Parameters for Surface Roughness in High Speed CNC Turning of EN-24 Alloy Steel using Response Surface Methodology, International Journal of Engineering Research and Applications, Vol. 4, Issue 5 (2014) 153 - 160

[22] Soni, V., Mondal, S. and Singh, B., Process Parameters Optimization in Turning of Aluminum using a New Hybrid Approach, International Journal of Innovative Science, Engineering, and Technology, Vol. 1, Issue 3 (2014) 418 - 423

[23] Shunmugesh, K., Panneerselvam, K. and Amal, G., Optimization of Turning Parameters with Carbide Tool for Surface Roughness Analysis using Response Surface Methodology, International journal of research in Aeronautical and Mechanical Engineering, Vol. 2, Issue 6 (2014) $17-27$

[24] Kumar, M. S., A Detailed Comparison among Dry, Wet and Gas Cooled Machining of Super Duplex Stainless Steel, Global Journal of Researches in Engineering: A Mechanical and Mechanics Engineering, Vol. 14, Issue 7 (2014) 17 - 25

[25] Sastry, M. N., Devi, K. D. and Reddy, K. M., Analysis and Optimization of machining Parameters using Design of Experiments, Industrial Engineering Letters, Vol. 2, No. 9 (2012) $23-32$

[256 Revankar, G. D., Shetty, R., Rao, S. S., and Gaitonde, V. N., Response Surface Model for Surface Roughness during Finish Turning of Titanium Alloy under Minimum Quantity Lubrication, International Conference on Emerging Trends in Engineering and Technology, Dec. $7-8$ (2013) $78-84$

[27] Mahajan, C. K., Mote, M. L., Patil, B. V. and Patil, H. G., Formulation and Simulation of a Field Data Based Model for the Turning process by using Response Surface Method, International Journal of Advanced Scientific and Technical Research, Vol. 2, Issue 3 (2013) $355-370$

[28] Shihab, S. K., Khan, Z. A., Mohammad, A. and Siddiquee, A. N., Optimization of Surface Integrity in Dry Hard Turning using RSM, Sadhand, Vol. 39, Part 5 (2014) 1035 - 1053

[29] Gupta, U. and Kohi, A., Experimental Investigation of Surface Roughness in Dry Turning of AISI 4340 Alloy Steel using PVD- and CVD-Coated Carbide Inserts, International Journal of Innovations in Engineering and Technology, Vol. 4, Issue 1 (2014) 94 - 103

[30] Khan, M. A., Kittur, J. K. and Kohir, V. D., Study and Analysis of Effect of Cutting Parameters on Cutting Forces and Surface Roughness, Advanced Engineering and Applied Sciences,: An International Journal, vol. 5, No. 3 (2015) 63 - 73

[31] Devkumar, V., Sreedhar, E. and Prabakaran, M. P., Optimization of Machining Parameters on AL 6061 Alloy using Response Surface methodology, International Journal of Applied Research, Vol. 1, No. 7 (2015) $01-04$

[32] Devi, K. D., Babu, K. S. and Reddy, K. H., Mathematical Modeling and Optimization of Turning process Parameters using Response Surface Methodology, International Journal of Applied Science and Engineering, Vol. 13, No. 1 (2015) 55-68

[33] Rajpoot, B. S., Moond, D. R. and Shrivastava, S., Investigating the effect of Cutting Parameters on the Average Surface Roughness and materials Removal Rate during Turning of Metal Matrix Composite using Response Surface Methodology, International Journal on Recent and Innovation Trends in Computing and Communication, Vol. 3, Issue 1 (2015) 241 247 
[34] Khidhir, B. A., A-Oqaiel, W. and Kareem, P. M., Prediction Models by Response Surface Methodology for Turning Operation, American Journal of Modeling and Optimization, Vol. 3, No. 1 (2015) $1-6$

[35] Agrawal, S., Guar, M. K., Kasdekar, D. K., Agrawal, S. and Malvi, C. S., Optimal Machining Condition for Turning of Hard Porcelain using Response Surface Methodology, European Journal of Advances in Engineering and Technology, Vol. 2, No. 5 (2015) 44 - 51

[36] Ranganath, M. S., Vipin, Kumar, N., and Kumar, R., Experimental Analysis of Surface Roughness in CNC Turning of Aluminum using Response Surface Methodology, International Journal of Advanced Research and Innovation, Vol. 3, Issue 1 (2015) 45 - 49

[37] Chandra, B. S. and Prasad, M. V. R. D., Parameter Optimization while Dry Turning AISI 1045 Steel using CBN Tool by Response Surface Methodology, GE International Journal of Engineering Research, Vol. 3, Issue 7 (2015) 69 - 82

[38] Kassab, S. Y. and Khoshnaw, Y. K., The Effect of Cutting Tool Vibration on Surface Roughness of Work-piece in Dry Turning Operation, Engineering and technology, Vol. 25, No. 7 (2007) $879-889$

[39] Han, X., Wang, M. and Ouyang, H., Vibration of Work-Pieces during Turning Operations, Journal of Physics: Conference Series 181, http://iopscience.iop.org/1742-6596/181/1/012032 (2009) $1-7$

[40] Cahuc, O., K'nevez, J Y., Gerard, A., Darnis, P., Albert, G., Bisu, C. F., and Gerard, C., SelfExcited Vibrations in Turning: Cutting Moment Analysis, International Journal of Advanced manufacturing Technology, version $1-9$ (2010) $1-9$

[41] Delijaicov, S., Leonardi, F., Bordinassi, E. C., and Batalha, G. F., Improved Model to predict Machined Surface Roughness based on the Cutting Vibrations signal during Hard Turning, Archives of Materials Science and Engineering, Vol. 45, Issue 2 (2010) 102 - 107

[42] Rogov, V. A. and Siamak, G., Optimization of Surface Roughness and Vibration in Turning of Aluminum Alloy AA2024 Using Taguchi Technique, International Journal of Mechanical, Aerospace, Industrial, Mechatronic and Manufacturing Engineering Vol. 7, No. 11 (2013) 2330 $-2339$

[43] Rogov, V. A. and Siamak, G., The Effect of Tool Construction and Cutting Parameters on Surface Roughness and Vibration in Turning of AISI 1045 Steel Using Taguchi Method, Modern Mechanical Engineering, 4 (2014) 8 - 18 